\title{
Methylxanthine and catechin content of fresh and fermented cocoa beans, dried cocoa beans, and cocoa liquor
}

\author{
Pedro P. Peláez ${ }^{1, ~ *}$; Inés Bardón'; Pedro Camasca² \\ ${ }^{1}$ Universidad Nacional Agraria de la Selva, Facultad de Ingeniería en Industrias Alimentarias. Av. Universitaria Km. 1.5, \\ Tingo María, Peru. \\ ${ }^{2}$ Cooperativa Agraria Cafetalera Divisoria Ltda., Caserio Mapresa km. 4.40 C.F.B. Santa Martha, Leoncio Prado, \\ Ниánисо, Peru.
}

Received May 23, 2016. Accepted November 07, 2016.

\begin{abstract}
The theobromine and catechin content can affect the quality of cocoa liquor and is influenced by cacao variety, production area (PA), and fermentation, as well as the method of drying beans (FDB) and cocoa liquor production (CLP). This study examined variations in methylxanthine and catechin levels in fresh and fermented cocoa beans, dried cocoa grains, and in cocoa liquor from Trinitario, Criollo, and Forastero cacao varieties. A total of 123 cocoa bean samples from three Peruvian PAs at different altitudes, Tingo María (TM), San Alejandro (SA), and Curimana (CU), were evaluated. The theobromine (Tb) and caffeine (Cf) contents in fresh cocoa beans were affected by both cocoa type and PA. The caffeine content was higher in Trinitario cacao than in Criollo and Forastero varieties $(\mathrm{p} \leq 0.05)$. The Tb and CF contents decreased in dry cocoa grain and was affected by FDB ( $\mathrm{p} \leq 0.05)(1.449 \pm 0.004$ to $1.140 \pm 0.010$ and $0.410 \pm 0.03$ to $0.165 \pm 0.02 \mathrm{~g} \mathrm{~Tb}$ and $\mathrm{C}$, respectively, per $100 \mathrm{~g}$ dry weight). Cocoa beans from Tingo María, which has the highest altitude, had higher $\mathrm{Tb}$ and $\mathrm{CF}$ contents than those from other PAs. The catechin (C) and epicatechin (EC) contents were affected by the FDB and CLP, and were highest in fresh cocoa beans from the Tingo María area (range: 0.065 \pm 0.01 to $0.020 \pm 0.00 \mathrm{~g} \mathrm{C} / 100 \mathrm{~g})$. The $\mathrm{C}$ and EC contents decreased during FDB and CLP $(0.001 \mathrm{~g} \mathrm{C} / 100 \mathrm{~g}$ of cocoa liquor). Taken together, these results show that higher concentrations of $\mathrm{Tb}, \mathrm{Cf}, \mathrm{C}$, and $\mathrm{EC}$ are present in fresh cocoa beans. Moreover, the cocoa variety influenced cocoa liquor quality. Overall, cocoa from the Tingo María PA had the most desirable chemical composition.
\end{abstract}

Keywords: HPLC; methylxanthines; theobromine; caffeine; catechin; epicatechin; cocoa.

\section{Introduction}

The post-harvest handling of cocoa is of critical importance to product quality, and if performed according to industry and market standards, can result in a better market price (Quarmine et al., 2012). Cocoa is a popular foodstuff worldwide and has high acceptance by consumers (Sarriá et al., 2015). Cocoa beans are the main cocoa product, and can act as a stimulant because of their theobromine and caffeine content (Araujo et al., 2014). Multiple health benefits of cocoa can be attributed to its enrichment in polyphenols, which can modulate oxidative effects associated with the development of cardiovascular and cerebrovascular diseases, as well as certain types of cancer (Giacometti et al., 2016; Ioannone et al., 2015).

The three major genetic groups of cocoa are Criollo, Forastero and Trinitario, which is a hybrid of Criollo and Forastero (Saltini et al., 2013). Criollo cocoa trees are relatively rare and less robust compared to other varieties. The crown of the Criollo tree is round, and its pale green leaves are small and oval. Cocoa beans are ivory white. Criollo cocoa is characterized by elongated cobs that are green and red when the beans are immature, and as they ripen they turn yellow and orange-red. Cocoa beans from Criollo trees are desirable because of their nutty and fruity flavor.

\footnotetext{
* Corresponding author

E-mail: pedro.pelaez@unas.edu.pe (P. Peláez).
} 
Criollo beans require between two and three days to ferment, and are very aromatic. Based on these qualities, Criollo beans have the commercial designation "fine cocoa" (Navia and Pazmiño, 2012). Meanwhile, Forastero, or Amazon, cocoa trees have violet staminodes, with cobs that turn yellow upon ripening. The cobs are grooved and slightly rough with smooth and rounded ends. The shells of Forastero cocoa beans are thick with a lignified mesocarp, and the beans themselves are flattened with purple cotyledons. Chocolate made from Forastero cocoa has a basic flavor. Trinitario cocoa is a polymorphic hybrid that carries Criollo intermediates and a Forastero strain that has relevant disjunction with Trinitario descendants. Among the tested strains, Trinitario cocoa has intermediate quality (Navia and Pazmiño, 2012).

The chemical composition of cocoa beans and their byproducts is complex and varies depending on the bean type, geographical area and maturity, as well as the fermentation and drying method (Bortolini et al., 2016). Cocoa contains methylxanthine alkaloids with a purine base (e.g., theobromine, caffeine and theophylline); these compounds have stimulatory activity. Theobromine $\left(\mathrm{C}_{7} \mathrm{H}_{8} \mathrm{~N}_{4} \mathrm{O}_{2}\right.$, 3,7-dimethylxanthine or 3,7-dihydro-3,7-dimethyl-1Hpurine-2,6-dione) is the main methylxanthine in cocoa that represents $\sim 4 \%$ of cocoa butter, or between 0.8 and $2 \%$ of total cocoa bean dry weight (Carrillo et al., 2014). The quantity of the xanthine alkaloid caffeine in cocoa averages around $0.2 \%$, and varies depending on bean type, plant species, and degree of fermentation (Carrillo et al., 2014). Meanwhile, theophylline in cocoa is present at very low amounts. Menguy et al. (2009) reported that fresh cocoa had theobromine and caffeine contents of 27 and $6.1 \mathrm{mg} \mathrm{g}^{-1}$, respectively, whereas fermented cocoa had 21 and $4 \mathrm{mg} \mathrm{g}^{-1}$, respectively. Although alkaloids do not undergo chemical transformations during fermentation, about $30 \%$ of alkaloids are eliminated by diffusion and migration to the outside of the bean
(Camu et al., 2008). The bitter taste of cocoa is mostly influenced by the purine content (theobromine and caffeine), and, by phenolic compounds (Kongor et al., 2016; Brunetto et al., 2007).

Catechin is a component of cocoa tannins (Pedan et al., 2015) which contribute to bean color and astringency, and is soluble in ethanol. Cocoa beans contain four types of catechins, of which (-)-epicatechin is the main type (92\% of total).

Cocoa beans also contain a variety of bioactive compounds, including polyphenols, the content of which can differ substantially between beans and cocoa derivatives. Among polyphenols present in cocoa are quercetin, isoquercitrin (quercetin 3-O-glucoside), hyperoside (quercetin 3-O-galactoside), naringenin, luteolin, and apigenin. Cocoa beans are rich in flavonoids, mainly flavanols, as well as flavones, anthocyanins, and other phenolic compounds (Torres, 2012).

Most initial pre-industrial processing of cocoa beans, including fermentation and sun drying, is performed at harvest. These processes are important to develop characteristic aromas and aroma precursors in chocolate. After harvesting the cob, cocoa beans are removed and carried to wooden boxes where fermentation takes place for either 2 to 3 days for Criollo cocoa beans, or 5 to 7 days for Forastero cocoa beans (Gil, 2012). During cocoa bean fermentation, polyphenols diffuse from cellular compartments and are oxidized to produce insoluble high molecular weight tannins. These oxidation reactions are catalyzed by polyphenol oxidase, which can be inactivated strongly during the first day of fermentation, such that the enzymatic activity falls from $50 \%$ full activation to $6 \%$ between days 1 and 2 . The main objective of drying is to reduce grain humidity (to 5-7\%) to decrease the likelihood of fungal contamination and facilitate storage and transport.

To our knowledge, there are no studies on the chemical composition of cocoa or cocoa byproducts from different cocoa varieties grown in Peru. Such information 
would be important given that loss of catechins and others polyphenols that occurs during post-harvest, pre-industrialization, and industrialization processes can lessen product quality (Giacometti et al., 2015).

This study sought to assess variations in methylxanthine and catechin contents of fresh cocoa beans, fermented cocoa grains, dry cocoa grains and cocoa liquor. The samples were from Tingo María (TM), Huánuco department, as well as San Alejandro (SA) and Curimana (CU) in the Ucayali department in Peru. Tingo María has the highest altitude, and Curimana has the lowest.

\section{Materials and methods}

\subsection{Cocoa beans and reagents}

A total of 82 samples of cocoa pods were collected in the Tingo María area (TM) at 660 meters above sea level (MASL) and $09^{\circ} 17^{\prime} 08^{\prime \prime}$ south latitude, $75^{\circ} 59$ ' 52" west latitude, whereas 21 samples were from the San Alejandro area (SA) at 217 MASL and $08^{\circ} 49^{\prime} 44^{\prime \prime}$ south latitude, $75^{\circ}$ 12' 44" west latitude. Twenty samples from the Curimana area (CU) were taken at 180 MASL and $08^{\circ} 27^{\prime}$ 51" south latitude, at $75^{\circ} 09^{\prime}$ 03" north latitude. Samples were collected with the support of the Cooperativa Agraria Cafetalera Divisoria Ltda., using information from farmers about trees that produce grains with special flavors and aromas. Theobro-mine $\geq$ $99.0 \%$, anhydrous caffeine, catechin $\geq$ 98\%, and methanol (Sigma, St. Louis, MO, USA) were used as standards. The following compounds isolated from green tea and were also purchased from Sigma: epicatechin $\geq 98 \%$, epigalloca-techin gallate $\geq 80 \%$ (HPLC), epigalloca-techin $\geq$ $95 \%$, and epicatechin gallate $\geq 98 \%$. Ethanol (99.99\%), glacial acetic acid, and deionized distilled water were from Merck.

\subsection{Preparation of cocoa sample and} extract

Samples from fresh cocoa pods were immediately transported to the laboratory where grain samples were cracked and extracted before drying at $35^{\circ} \mathrm{C}$ for $8 \mathrm{~h}$ and at $65{ }^{\circ} \mathrm{C}$ for 18 hours. The final humidity of the grains was $7 \%$. Grains were stored in polyethylene bags at $-20{ }^{\circ} \mathrm{C}$ for later use. Dried fresh beans were peeled manually and ground in a grinder before theobromine, caffeine, and catechins were extracted from $0.02 \mathrm{~g}$ ground cocoa in $5 \mathrm{ml}$ of acetic acid $0.3 \%$, and HPLC grade methanol $(85: 15)$. The mixture was vortexed for $15 \mathrm{~min}$ and a $500 \mu \mathrm{g} / \mathrm{mL}$ solution was prepared, centrifuged, and passed through a microfilter prior to injection into an HPLC (see below).

Fresh, fermented, and dry samples were also examined. To obtain fermented beans micro-fermentation was performed for different time periods (48, 96 and 120 hours). For this procedure, $2 \mathrm{~kg}$ cocoa grain was separated from the cocoa slime mass in a nylon bag or plastic netting. The nylon bag maintained the "inserted product" as a separate sample but was exposed to the same conditions as the remaining grains. The bag was then inserted in the top $(30 \mathrm{~cm})$ of a fermentation box that contained a larger amount $(200 \mathrm{~kg})$ of cocoa slime. The "inserted product" was inverted at the same time as the rest of the cocoa mass in the slime (48 and 96 hours), and the total fermentation time was 120 hours. During micro-fermentation we took samples (10 grains) at $0,48,96$ and 120 hours for evaluation. These samples were placed in polyethylene bags and transported to the laboratory in a container with ice.

Dried cocoa samples were obtained by sun drying to $7 \%$ humidity. Fresh, fermented (48, 96 and 120 hours), and dried beans were peeled manually, milled in a grinder, centrifuged, filtered and extracted for analysis of theobromine, caffeine and catechin compounds.

\subsection{HPLC analysis of cocoa bean chemical contents}

Chromatographic analysis was performed using reverse phase liquid chromatography on a LC-10 AT VP Scientific apparatus (Shimadzu, MD, USA) that included: a Shimadzu DGU degasser-14A; a manual Rheodyne 7725i injector; a management 
pack solvent that included a quaternary pump, a Shimadzu LC-10 AT and one column oven (Shimadzu CTO-10AS). A Shimadzu UV-Vis SPD_10AV detector was used to determine the chromategraphic peak purity at SCL interface 10AV. Peak identification and integration was performed using Shimadzu software Class-VP version 6.13 SP2. Chromatographic separations were performed with a guard ultra-cartridge C18 column $(20 \mathrm{~mm}$ x 4 mm, Restek, Catalog: 917450 220) and an Ultra C18 column (150 mm x 4.6 mm x $5 \mu \mathrm{m}$, Restek, Catalog: 9174565). The column was maintained at $35^{\circ} \mathrm{C}$. The mobile phase was a mixture of $24.9 \%$ methanol, $75.0 \%$ distilled deionized water, acetic acid (100:0.1), and the flow rate was $1 \mathrm{ml} / \mathrm{min}$. Solutions were filtered with a $0.2 \mu \mathrm{m}$ nylon microfilter prior to injection of a $20 \mu \mathrm{l}$ sample volume. Simultaneous chromatographic analysis of theobromine, caffeine, and catechins in selected samples was performed at a wavelength of $210 \mathrm{~nm}$, whereas the selected mobile phase was 20\% methanol: $80 \%$ water, acetic acid (100:0.1).

\subsection{Determination of methylxanthine and catechin content in cocoa}

The HPLC apparatus described above was also used to quantify theobromine (Tb), caffeine (Cf) (Menguy et al., 2009), catechin (C), epicatechin (EC), epigallocatechin (EGC), epicatechin gallate (ECG) and epigallocatechin gallate (EGCG) (Meng et al., 2009) in three samples for fresh, fermented (48, 96, and 120 hours) grain, and liquor samples according to previously described methods.

\subsubsection{Preparation of theobromine and caffeine standards}

Before injecting samples into the HPLC instrument, calibration with theobromine standards was performed. $1 \mathrm{mM}$ and $3 \mathrm{mM}$ stock solution was diluted in HPLC grade deionized distilled water to prepare 3,6 , $12,24,36,48$, and $60 \mu \mathrm{M}$ and $1.5,3,6,12$, 18,24 , and $30 \mu \mathrm{M}$ theobromine and caffeine solutions, respectively, which were used to generate standard curves. Aliquots of theobromine and caffeine stock solutions were stored at $-20^{\circ} \mathrm{C}$ to preserve their stability and quality, and solutions were filtered prior to HPLC injection.

\subsubsection{Preparation of catechin standards}

Stock solutions (500 ppm) were used for catechin, epicatechin, epicatechin gallate, and epigallocatechin gallate, whereas the epigallocatechin stock solution was 418 ppm. The stock solutions were stored at $20{ }^{\circ} \mathrm{C}$. A mixture of standards was prepared to generate curves simultaneously. Five concentrations were measured in triplicate such that the final solution concentrations were: $1.72,17.23,25.84,51.68,103.36$ $\mu \mathrm{M}$ (catechin); 2.07, 4.13, 41.34, 82.68, $165.36 \mu \mathrm{M}$ (epicatechin); 2.26, 15.82, $31.65,63.30, \quad 126.59 \mu \mathrm{M}$ (epicatechin gallate); $1.09,10.91,16.36,32.72,76.36$ $\mu \mathrm{M}$ (epigallocatechin gallate); and 1.63, $8.16,16.33,48.98,97.95 \mu \mathrm{M}$ (epigallocatechin).

\subsection{Cocoa genotyping}

Cocoa genotype selection was based on a comparison of the $\mathrm{Tb} / \mathrm{Cf}$ ratio with $\mathrm{Cf}$, which indicates the cocoa genotype, and was calculated using previously described methodology (Carrillo et al. 2014). Cocoa index of $\mathrm{Tb} / \mathrm{Cf}<3,3-9$, and $>9$ is consistent with Criollo type, Trinitario type, and Forastero type, respectively.

\subsection{Statistical analysis}

$\mathrm{Tb}, \mathrm{Cf}$, and catechin content in fresh, fermented, and dried cocoa grains, as well as cocoa liquor were statistically evaluated, and a completely randomized design was used with three replications (Rios, 2012). Statistical differences were evaluated by a Tukey test. All statistical analyses were performed using STATGRAPHICS Centurion $\mathrm{XV}$ software version 2.15.06.

\section{Results and discussion}

\subsection{Cocoa genotyping}

Theobromine and caffeine contents of fresh cocoa beans were analyzed by HPLC at a wavelength of $210 \mathrm{~nm}$. To quantify theobromine and caffeine contents we first generated standard curves for both compounds. These curves showed that theobromine $(\mathrm{Tb})$ eluted first, followed by caffeine (Cf) (Fig. 1). 


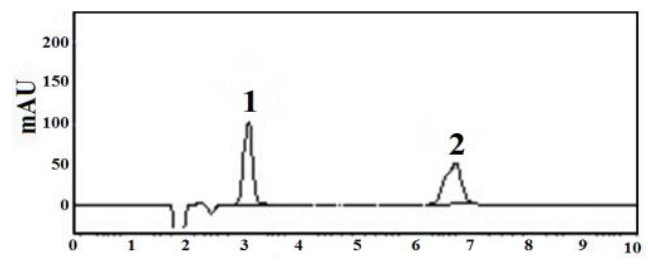

Figure 1. Chromatographic profile of theorbomine (1) and caffeine (2f) standards.
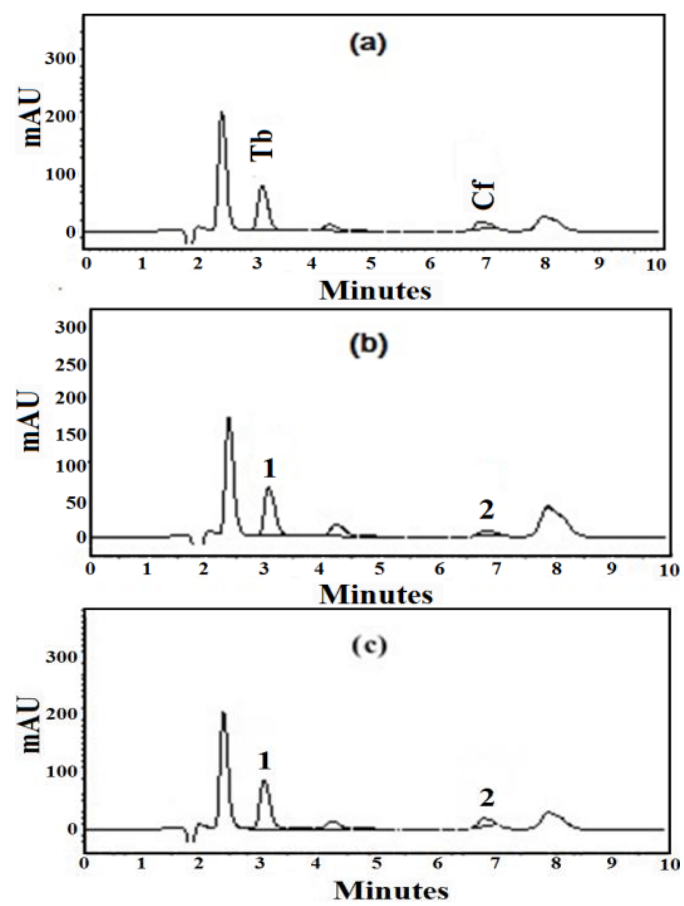

Figure 2. Chromatographic profile of fresh cocoa beans from Tingo María (a), San Alejandro (b), and Curimana (c) areas; Theobromine (1) and caffeine (2).

Standard curves for $\mathrm{Tb}$ and $\mathrm{Cf}$ with seven points and three replications were generated using the equations below:

$$
\begin{gathered}
\text { Area }=29441 \mu \mathrm{M} \mathrm{Tb}+18936, \mathrm{r} 2=0.9962 \\
\text { Area }=33519 \mu \mathrm{M} \mathrm{Cf}+5963, \mathrm{r} 2=0.9962
\end{gathered}
$$

\section{Table 1}

$\mathrm{Tb}$ and $\mathrm{Cf}$ contents and $\mathrm{Tb} / \mathrm{Cf}$ ratios of cocoa samples from Tingo María, San Alejandro, and Curimana areas

\begin{tabular}{ccccc}
\hline Place of & & $\mathrm{Tb}$ & $\mathrm{Cf}$ & Index of \\
\cline { 2 - 5 } Production & Code & $(\mathrm{g} / 100 \mathrm{~g}$ of cocoa $)$ & $(\mathrm{g} / 100 \mathrm{~g}$ of cocoa $)$ & $\mathrm{Tb} / \mathrm{Cf}$ \\
\hline \multirow{3}{*}{ Tingo María } & OC1 & $6.195 \pm 0.189$ & $1.706 \pm 0.108$ & $3.65 \pm 0.132$ \\
& JC0 & $6.811 \pm 0.129$ & $1.465 \pm 0.051$ & $4.66 \pm 0.149$ \\
& TN2 & $7.359 \pm 0.203$ & $1.526 \pm 0.045$ & $4.83 \pm 0.137$ \\
\hline \multirow{3}{*}{ San Alejandro } & TMG1 & $6.460 \pm 0.029$ & $2.083 \pm 0.025$ & $3.10 \pm 0.053$ \\
& CCM1 & $5.774 \pm 0.109$ & $1.055 \pm 0.016$ & $5.47 \pm 0.020$ \\
& GCZ6 & $7.606 \pm 0.043$ & $1.208 \pm 0.018$ & $6.30 \pm 0.057$ \\
\hline \multirow{2}{*}{ Curimana } & VCM4 & $6.025 \pm 0.217$ & $1.804 \pm 0.054$ & $3.34 \pm 0.108$ \\
& VCM2 & $6.879 \pm 0.125$ & $1.778 \pm 0.014$ & $3.87 \pm 0.051$ \\
& CMA4 & $5.735 \pm 0.09^{\mathrm{a}}$ & $1.476 \pm 0.020$ & $3.89 \pm 0.058$ \\
\hline
\end{tabular}

Values represent the average of \pm SEM, $n=320 \mu \mathrm{L}$ injections of HPLC. Theobromine (1) and caffeine (2) of fresh cocoa beans from Tingo María (a), San Alejandro (b), and Curimana (c) areas. Table 1 shows the theobromine (Tb) and caffeine (Cf) content together with the $\mathrm{Tb} / \mathrm{Cf}$ ratio. The index relationship of $\mathrm{Tb} / \mathrm{Cf}$ vs. Cf in beans from Tingo María (TM), San Alejandro (SA), and Curimana (CU) areas ranged between 3.10 and 6.30 (Fig. 3). Values between three and nine were previously shown to correspond to Trinitario cocoa (Fig. 3), whereas values less than three and greater than nine are representative of Criollo and Forastero cocoa, respectively (Carrillo et al., 2014; Zambrano et al., 2010).

Criollo cocoa is less bitter, which is likely due to its lower concentration of theobromine relative to other genetic groups. Different types of cocoa are known to have different methylxanthine contents, and these differences are useful for differentiating cocoa genotypes. Our statistical analysis showed that the methylxanthine content was indeed affected by cocoa type and production area $(\mathrm{p} \leq 0.05)$. Tests based on average values for a given cocoa growth area showed that the theobromine content in samples was lower for Trinitario cocoa, whereas this type had high caffeine content (Table 1). The $\mathrm{Tb} / \mathrm{Cf}$ ratio is an important parameter for cocoa, since lower ratios are typical of Criollo cocoa as opposed to Trinitario or Forastero cocoas. High levels of caffeine are characteristic of high-quality Criollo cocoa (Trognitz et al., 2013). 

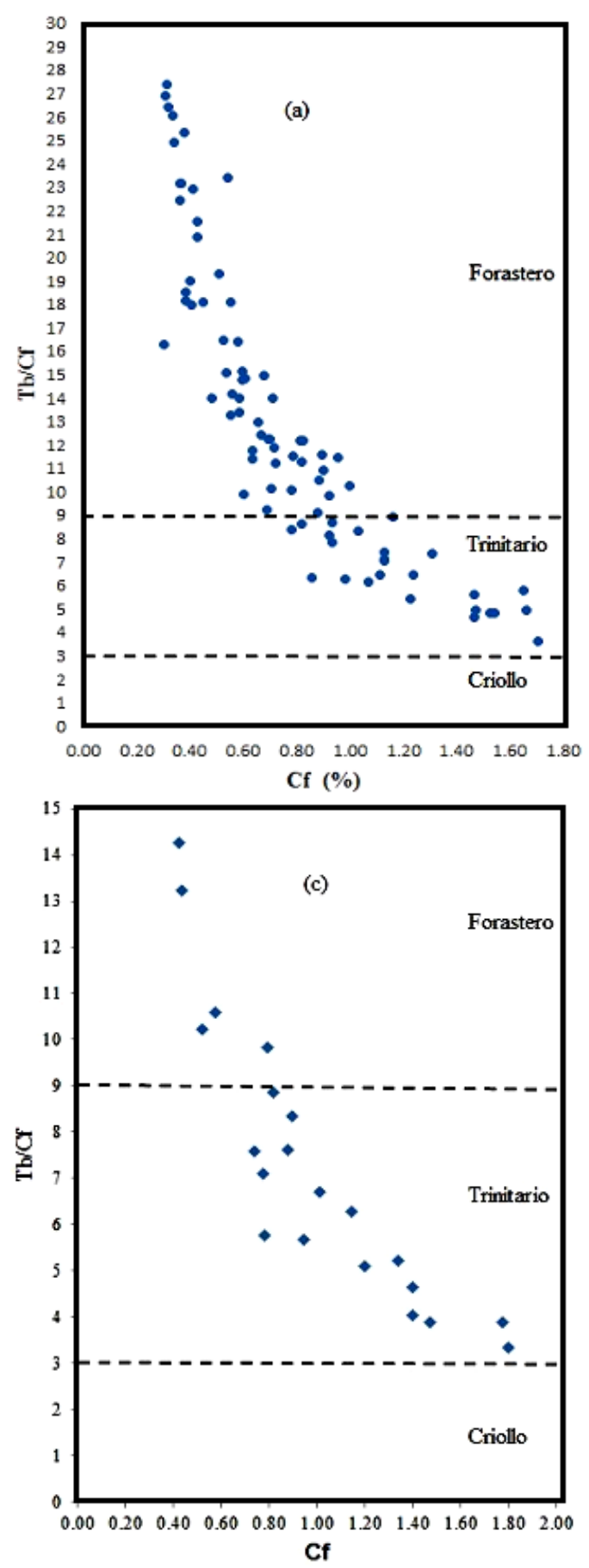

3.2 Tb, Cf, C and EC standard curve

A chromatographic profile of standard solutions showed an order of elution that is consistent with earlier reports, although there was a change in retention time (Fig. 4). The composition of the mobile phase (80:20) was acetic acid (0.1\%) and methanol.

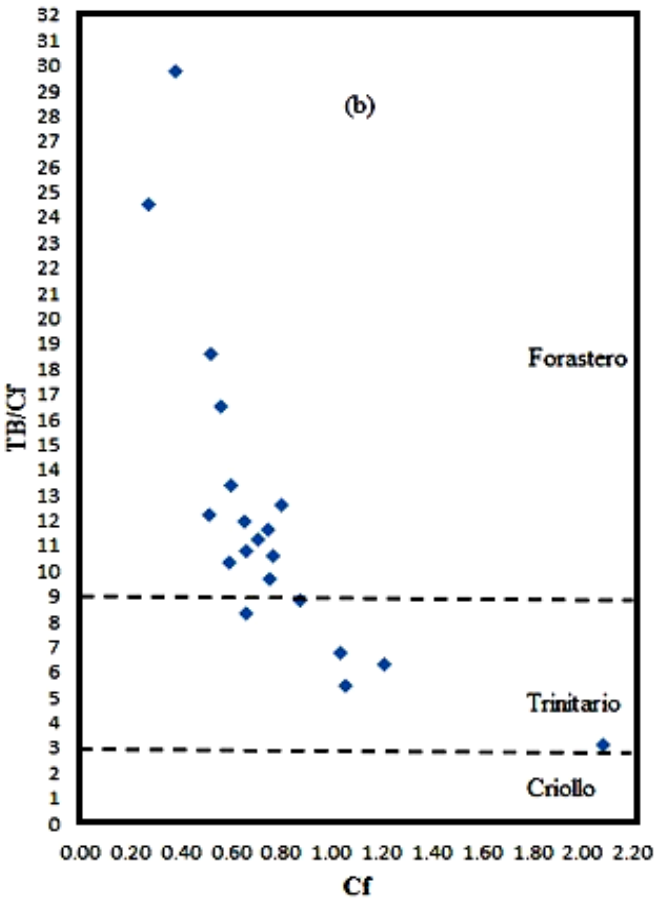

Figure 3. Ratio of theobromine/caffeine $(\mathrm{Tb} / \mathrm{Cf})$ vs. Cf for cocoa samples from Tingo María (a), San Alejandro (b), and Curimana (c) areas.

A mixture of 5 concentrations for each standard was evaluated with 3 replicates for each concentration. The $r^{2}$ values ranging between 0.9984 and 0.9999 indicated a strong and almost perfect positive relationship. The minimum and maximum concentration of an analyte could be calculated within the linear range of the standard curve. 


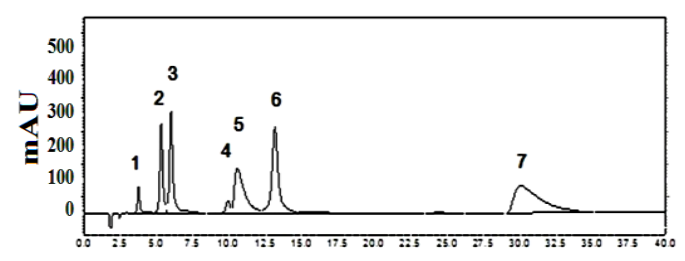

Minutes

Figure 4. Chromatograms of standards for theobromine (1), epigallocatechin (2), catechin (3), caffeine (4), epigallocatechin (5), epicatechin (6), and epicatechin gallate (7).

Table 2

Equation standards to quantify the compounds detected in samples

\begin{tabular}{lcc}
\hline Standards & Equations* & $\mathrm{r}^{2}$ \\
\hline Theobromine & $\mathrm{Y}=155708 \mathrm{X}-5953.8$ & 0.9995 \\
Catechin & $\mathrm{Y}=175948 \mathrm{X}-15985$ & 0.9999 \\
Caffeine & $\mathrm{Y}=153598 \mathrm{X}+26094$ & 0.9984 \\
Epicatechin & $\mathrm{Y}=167567 \mathrm{X}+104559$ & 0.9990 \\
\hline *Y = area of curve; $\mathrm{X}=$ ppm of compound.
\end{tabular}

3.3 Theobromine, caffeine, catechin and epicatechin content

The bitter taste of cocoa is largely influenced by the methylxanthine (theobromine and caffeine) content, and to a lesser degree, by phenolic compounds. Indeed, Criollo cocoa has a lower bitter index due to its low theobromine content (Trognitz et al., 2013). As such, we used HPLC to analyze methylxanthine contents of fresh cocoa beans from the Tingo María, San Alejandro, and Curimana PAs (Fig. 5a-c). The chromatograms showed high theobromine contents, and were similar to previous studies on cocoa beans (Fig. 5; Pereira-Caro et al., 2013). Caffeine and theobromine are the most abundant methylxanthines in cocoa and their physiological effects are notable. The health-promoting benefits of cocoa are so pronounced that the therapeutic properties of chocolate have been the subject of several studies (Franco et al., 2013).

\subsection{Theobromine and caffeine}

Measurements of theobromine ( $\mathrm{Tb})$ and caffeine $(\mathrm{Cf})$ content in samples of fresh, fermented, and dried beans, as well as cocoa liquor showed that, relative to other production stages, fresh cocoa grains have higher Tb contents, with values that varied between 1.088 and $1.449 \mathrm{~g} \mathrm{~Tb} / 100 \mathrm{~g}$ (Table 3). Fresh cocoa grain from Tingo María had the highest $\mathrm{Tb}$ content, which was higher than those from an earlier investigation that reported values between 0.8622 and $0.8909 \mathrm{~g} \mathrm{~Tb} / 100 \mathrm{~g}$. This difference may be due to the extraction conditions used (Lo Coco et al., 2007).
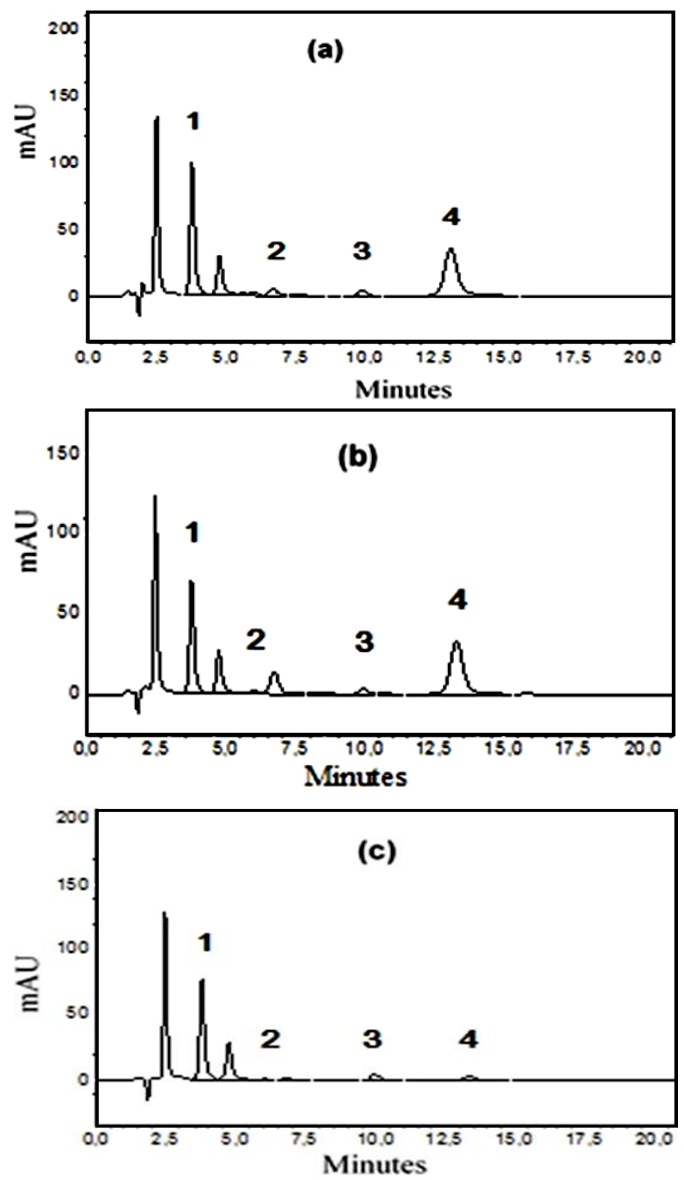

Figure 5. Chromatographic profiles of fresh cocoa beans, $\lambda=210 \mathrm{~nm}$, from Tingo María (a), San Alejandro (b), and Curimana (c) PAs. Chromatographic peaks for theobromine (1), catechin (2), caffeine (3) and epicatechin (4) are shown.

Analysis of $\mathrm{Tb}$ results revealed that processed cocoa and liquor had a statistically significant difference $(\mathrm{p} \leq 0.05)$ in $\mathrm{Tb}$ contents. Moreover, a Tukey test showed that fresh cocoa beans had a higher theobromine content and that there was no statistical difference between the dry fermented samples and cocoa liquor. 


\section{Table 3}

Theobromine $(\mathrm{Tb})$ and caffeine $(\mathrm{Cf})$ content in fresh cocoa beans, fermented cocoa $(48,96$, and 120 hours), dried grains, and liquor from the Tingo María (TM) San Alejandro (SA), and Curimana (CU) PAs. Expressed in dried base ${ }^{1}$

\begin{tabular}{|c|c|c|c|c|c|c|}
\hline \multirow{2}{*}{$\begin{array}{l}\text { Processing } \\
\text { stage }\end{array}$} & TM & SA & $\mathrm{CU}$ & $\mathrm{TM}$ & SA & $\mathrm{CU}$ \\
\hline & \multicolumn{3}{|c|}{$(\mathrm{g} \mathrm{Tb} / 100 \mathrm{~g}$ of cocoa $)$} & \multicolumn{3}{|c|}{ (g Cf/100 g of cocoa) } \\
\hline Fresh & $1.449 \pm 0.004$ & $1.088 \pm 0.009$ & $1.324 \pm 0.074$ & 0.410 & $0.204 \pm 0.01$ & 0.350 \\
\hline $48 \mathrm{~h}$ & $1.376 \pm 0.029$ & $1.047 \pm 0.020$ & $1.182 \pm 0.020$ & 0.317 & $0.168 \pm 0.01$ & 0.31 \\
\hline $96 \mathrm{~h}$ & $1.282 \pm 0.003$ & $1.002 \pm 0.019$ & $1.236 \pm($ & $0.277 \pm 0.02$ & $0.155 \pm 0.00$ & 0.182 \\
\hline $120 \mathrm{~h}$ & $1.241 \pm 0.011$ & $0.952 \pm 0.022$ & $1.063 \pm 0.043$ & $0.210 \pm 0.01$ & $0.100 \pm 0.00$ & $0.139 \pm 0.01$ \\
\hline Dried & $1.156 \pm 0.005$ & $0.885 \pm 0.012$ & $0.854 \pm 0.011$ & $0.200 \pm 0.01$ & $0.088 \pm 0.00$ & $0.087 \pm 0.00$ \\
\hline Liquor & $1.140 \pm 0.010$ & $0.836 \pm 0.011$ & $0.940 \pm 0.106$ & $0.165 \pm 0.02$ & $0.077 \pm 0.00$ & $0.091 \pm 0.01$ \\
\hline
\end{tabular}

${ }^{1}$ Values represent the average of \pm SEM, $n=3$ injection of HPLC. The volume of each injection was $20 \mu \mathrm{L}$.

During processing that occurs between harvest and liquor production, the theobromine content decreases (Gil, 2012), but the chemical quality improves through reductions in alkaloid and polyphenol contents that influence the organoleptic characteristics of cocoa (Trognitz et al., 2013). During fermentation, the theobromine content in cocoa from the Tingo María, San Alejan-dro, and Curimana PAs decreased by 21.33, 23.16 and $29 \%$, respectively, relative to fresh beans. Similarly, previous reports showed that theobromine content is reduced by $20 \%$ during fermentation, and this reduction decreases the bitterness of the beans (Trognitz et al., 2013; Brunetto et al., 2007).

Meanwhile, fresh cocoa beans had a higher $\mathrm{Cf}$ content that varied between $0.204 \pm$ 0.01 and $0.410 \pm 0.03 \mathrm{~g} \mathrm{Cf} / 100 \mathrm{~g}$. Fresh beans from Tingo María had the highest $\mathrm{Cf}$ content. Relative to earlier studies, the $\mathrm{Cf}$ contents found here were higher, and ranged from 0.0827 to $0.0908 \mathrm{~g} \mathrm{Cf} / 100 \mathrm{~g}$. These differences may again be attributed to different extraction conditions (Lo Coco et al., 2007).

Analysis of $\mathrm{Cf}$ results showed a statistically significant difference between postharvest cocoa and cocoa liquor $(p \leq 0.05)$

Analysis of $\mathrm{Cf}$ results showed a statistically significant difference between postharvest cocoa and cocoa liquorA Tukey test established that fresh cocoa beans had a significantly higher $\mathrm{Cf}$ content than the other processing stages, and that there was no significant difference between fermented and dried cocoa, or cocoa liquor. The caffeine content of cocoa from Tingo María, San Alejandro, and Curimana areas fell by $40.24 \%, 37.75 \%$, and $26 \%$ from fresh cocoa beans, respectively. Meanwhile, the methylxanthine content is generally higher during the first days of fermentation, and gradually decreases as fermentation proceeds (Brunetto et al., 2007).

The methylxanthine (theobromine and caffeine) content was affected by the FDB factor, and highlights that fresh beans from the Tingo María area have a higher content of $\mathrm{Tb}$ and $\mathrm{Cf}$ relative to other areas. These contents decreased during processing and liquor production to range from $1.449 \pm$ 0.004 to $0.140 \pm 1.010 \mathrm{~g} \mathrm{~Tb} / 100 \mathrm{~g}$ of sample and $0.410 \pm 0.03$ to $0.165 \pm 0.02 \mathrm{~g}$ $\mathrm{Cf} / 100 \mathrm{~g}$ of sample. There was a statistically significant difference between the fresh beans and cocoa liquor.

\subsection{Catechin and epicatechin}

The catechin (C) and epicatechin (EC) contents were next measured for fresh, fermented, and dried cocoa, as well as cocoa liquor from the different areas ( $\mathrm{g}$ per $100 \mathrm{~g}$ sample; Table 4). Fresh cocoa beans from the Tingo María area had a higher content of $\mathrm{C}(0.065 \pm 0.01-0.013 \pm 0.0 \mathrm{~g}$ $\mathrm{C} / 100 \mathrm{~g})$. These values were higher than those found earlier (0.0388-0.0434 g C/100 $\mathrm{g}$ of sample), the difference may be related to the presence of procyanidin (RabadanChávez et al., 2016). 


\section{Table 4}

Catechin (C) and epicatechin (EC) contents in cocoa beans: fresh (0 hours), fermented (48, 96, and 120 hours), dry grains and cocoa liquor from cocoa from Tingo María (TM) San Alejandro (SA), and Curimana (CU) PAs. Expressed as dried base ${ }^{1}$

\begin{tabular}{|c|c|c|c|c|c|c|}
\hline \multirow{2}{*}{$\begin{array}{l}\text { Processing } \\
\text { stage }\end{array}$} & $\mathrm{TM}$ & SA & $\mathrm{CU}$ & $\mathrm{TM}$ & SA & $\mathrm{CU}$ \\
\hline & \multicolumn{3}{|c|}{ (g C/100 g of cocoa) } & \multicolumn{3}{|c|}{ (g EC/100 $\mathrm{g}$ of cocoa) } \\
\hline Fresh & $0.065 \pm 0.01$ & $0.020 \pm 0.00$ & $0.026 \pm 0.00$ & $1.855 \pm 0.20$ & $1.291 \pm 0.01$ & $0.055 \pm 0.01$ \\
\hline $48 \mathrm{~h}$ & $0.053 \pm 0.01$ & $0.007 \pm 0.0$ & $0.023 \pm 0.00$ & $1.180 \pm 0.16$ & $0.760 \pm 0.04$ & $0.041 \pm 0.01$ \\
\hline $96 \mathrm{~h}$ & $0.027 \pm 0.00$ & $0.003 \pm 0.00$ & $0.017 \pm 0.00$ & $0.931 \pm 0.17$ & $0.393 \pm 0.08$ & $0.043 \pm 0.01$ \\
\hline $120 \mathrm{~h}$ & $0.016 \pm 0.00$ & $0.003 \pm 0.00$ & $0.011 \pm 0.00$ & $0.496 \pm 0.13$ & $0.375 \pm 0.05$ & $0.029 \pm 0.01$ \\
\hline Dried & $0.014 \pm 0.00$ & $0.002 \pm 0.00$ & $0.010 \pm 0.00$ & $0.504 \pm 0.06$ & $0.377 \pm 0.05$ & $0.033 \pm 0.02$ \\
\hline Liquor & $0.013 \pm 0.00$ & $0.001 \pm 0.00$ & $0.004 \pm 0.00$ & $0.139 \pm 0.01$ & $0.086 \pm 0.01$ & $0.022 \pm 0.01$ \\
\hline
\end{tabular}

${ }^{1}$ These values represent the average \pm SEM, $n=3$ injection of HPLC. The volume of each injection was $20 \mu \mathrm{L}$.

Statistical analysis of $\mathrm{C}$ results indicated that the $\mathrm{C}$ content differed with processing stage. A Tukey test showed that fresh cocoa beans had higher $\mathrm{C}$ contents than the other stages, and there was no statistically significant difference $(\mathrm{p} \leq 0.05)$ between fermented, dried, and liquor samples. This result is consistent with those presented in a study by Nazaruddin et al. (2006) that reported a decrease in the $\mathrm{C}$ content from $0.58 \pm 0.10 \mathrm{mg} / \mathrm{g}$ in mature beans to $0.07 \pm$ 0.00 in fermented and dried beans. In another study, the $\mathrm{C}$ content increased as the epicatechin content decreased. Specifically, during fermentation there was a marked increase $(68 \%, 0.29$ to $0.49 \mathrm{mg} / \mathrm{g})$ in $\mathrm{C}$ that decreased to $0.24 \mathrm{mg} / \mathrm{g}$ for sun dried grains (Gil, 2012).EC contents also varied according to processing stage. A Tukey test showed that EC contents in cocoa beans from the Tingo María, San Alejandro, and Curimana PAs were higher in fresh beans relative to other processing stages $(1.855 \pm 0.20 ; 1.291 \pm 0.01$, and $0.055 \pm 0.01 \mathrm{~g} \mathrm{EC} / 100 \mathrm{~g}$ of sample, respectively). Values for beans from the San Alejandro PA were similar to that seen in a study by Gil (2012, $1.27 \mathrm{~g} \mathrm{EC/100} \mathrm{g).}$ There was no statistically significant difference between beans and cocoa liquor, nor were there marked differences between the EC content of fermented and dried cocoa beans.

The EC content decreased during drying, reaching values between $0.022 \pm 0.01$ and $0.139 \pm-0.01 \mathrm{~g} \mathrm{EC} / 100 \mathrm{~g}$ of cocoa liquor
(Table 4); although the $0.377 \mathrm{~g} \mathrm{EC/100} \mathrm{g}$ value is almost equal to that reported earlier (Gil, 2012).

\section{Conclusions}

In the higher altitude Tingo María and San Alejandro PAs, Forastero and Trinitario cocoa are the most prevalent varieties, whereas in the Curimana PA, which has the lowest altitude, Forastero cocoa is the most common. Statistical analyses determined that cocoa type and PA affected the theobromine and caffeine contents $(\mathrm{p} \leq$ $0.05)$. Fresh cocoa beans had the highest theobromine and caffeine content, and the content decreased during fermentation and drying. Fresh beans from the PA with the highest altitude, Tingo María, had high theobromine and caffeine contents, suggesting that altitude may affect the chemical content of cocoa beans. The amount of theobromine and caffeine both decreased during fermentation, drying, and cocoa liquor production, (from $1.449 \pm 0004$ and $1.140 \pm 0.010$, and $0.410 \pm 0.03$ and 0.165 $\pm 0.02 \mathrm{~g} / 100 \mathrm{~g}$ of theobromine and caffeine, respectively); there was also a statistical difference between the contents in fresh beans and cocoa liquor. $\mathrm{C}$ and $\mathrm{EC}$ contents also differed according to processing stage, and were highest in fresh cocoa beans. Cocoa from the high altitude Tingo María PA had the highest $\mathrm{C}$ content that varied between $0.065 \pm 0.01$ and 0.020 $\pm 0.00 \mathrm{~g} \mathrm{C} / 100 \mathrm{~g}$ of beans. This content decreased during fermentation, drying, and 
liquor production, and reached values between $0.001 \pm 0.0$ and $0.013 \pm 0.0 \mathrm{~g}$ $\mathrm{C} / 100 \mathrm{~g}$ of liquor. Meanwhile EC concentrations varied between $0.055 \pm 0.01$ and $1.855 \pm 0.20 \mathrm{~g} \mathrm{EC} / 100 \mathrm{~g}$ for fresh beans and $0.022 \pm 0.01$ and $0.139 \pm 0.01 \mathrm{~g}$ $\mathrm{EC} / 100 \mathrm{~g}$ of liquor, with no statistical difference seen between fermented and dried samples. Together these results show that $\mathrm{Tb}, \mathrm{Cf}, \mathrm{C}$, and $\mathrm{EC}$ contents were affected by processing stage and PA, and were the highest in fresh cocoa beans harvested in the high altitude Tingo María area. The presence of polyphenols in cocoa samples and cocoa liquor indicate that cocoa products can have health benefits. Our results provide a basis for investigating the chemical characteristics of cocoa plantations and exploring how the functionality of cocoa can be improved in cocoa producing areas.

\section{References}

Araujo, R.; Fernandes, C.; Ribeiro, D.; Efraim, P.; Steinmacher, D.; Lieberei, R.; Bastide, P.; Araujo, T. 2014. Cocoa Quality Index A proposal. Food Control 46: $49-54$.

Bortolini, C.; Patrone, V.; Puglisi, E.; Morelli, L. 2016. Detailed analyses of the bacterial populations in processed cocoa beans of different geographic origin, subject to varied fermentation conditions. International Journal of Food Microbiology 236: 98-106.

Brunetto, M. Del R.; Gutiérrez, L.; Gallignani, M.; Zambrano, A.; Gómez, Á.; Romero, C. 2007. Determination of theobromine, theophylline and caffeine in cocoa samples by a high-performance liquid chromategraphic method with on-line sample cleanup in a switching-column system. Food Chemistry 100: 459467.

Camu, N.; De Winter, T.; Addo, S.K.; Takrama, J.S.; Bernaert, H.; De Vuyst, L. 2008. Fermentation of cocoa beans: influence of microbial activities and polyphenol concentrations on the flavour of chocolate. Journal of the Science of Food and Agriculture 88(13): 2288-2297.

Carrillo, L.C.; Londoño-Londoño, J.; Gil, A. 2014. Comparison of polyphenol, methylxanthines and antioxidant activity in Theobroma cacao beans from different cocoa-growing areas in Colombia. Food Research International 60: 273-280.

Franco, R.; Oñatibia-astibia, A.; Martínez-pinilla, E. 2013. Health Benefits of Methylxanthines in Cacao and Chocolate. Nutrients 5(10): 4159-4173.

Giacometti, J.; Jolić, S.M.; Josić, D. 2015. Cocoa Processing and Impact on Composition. Processing and Impact on Active Components in Food. Editorial Academic Press. USA. Pp. 605-612.

Giacometti, J.; Muhvic D.; Pavletic A.; Đudaric L. 2016. Cocoa polyphenols exhibit antioxidant, antiinflammatory, anticancerogenic, and antinecrotic activity in carbon tetrachlorideintoxicated mice. Journal of Functional Foods 23: 177-187.
Gil, Q.J.A. 2012. Stability and antioxidant activity of catechins present in Colombian cocoa during the processes of pre-industrialization and industrialization. Master's Thesis. Universidad de Antioquia, Medellin, Colombia. 119 p.

Ioannone, F.; Di Mattia, C.D.; De Gregorio, M.; Sergi, M.; Serafini, M.; Sacchetti, G. 2015. Flavanols, proanthocyanidins and antioxidant activity changes during cocoa (Theobroma cacao L.) roasting as affected by temperature and time of processing. Food Chemistry 174: 256-262.

Kongor, J., E.; Hinneh, M.; Van de Walle, D.; Afoakwa, E., O; Boeckx, P.; Dewettinck, Koen. 2016. Factors influencing quality variation in cocoa (Theobroma cacao) bean flavour profile - A review. Food Research International 82: 44-52.

Lo Coco, F.; Lanuzza, F.; Micali, G.; Cappellano, G. 2007. Determination of Theobromine, Theophylline, and Caffeine in by-Products of Cupuacu and Cacao Seeds by High-Performance Liquid Chromatography. Journal of Chromatographic Science 45(5): 273-275.

Meng, C.C.; Jalil, A.M.M.; Ismail, A. 2009. Phenolic and theobromine contents of commercial dark, milk and white chocolates on the Malaysian market. Molecules 14(1): 200-209.

Menguy, L.; Prim, D.; Carlin-sinclair, A.; Marc, I. 2009. The Determination of Methylxanthines in Chocolate and Cocoa by Different Separation Techniques: HPLC, Instrumental TLC, and MECC. Journal of Chemical Education 86(11): 1307.

Nazaruddin, R.; Seng, L.K.; Hassan, O.; Said, M. 2006. Effect of pulp preconditioning on the content of polyphenols in cocoa beans (Theobroma Cacao) during fermentation. Industrial Crops and Products 24(1): 87-94.

Navia, O.; Pazmiño, P. 2012. Improvement of Sensory Characteristics Cocoa CCN51 through the Addition of enzymes for Fermentation Process. Thesis. Escuela Superior Politécnica del Litoral. Facultad de Ingeniería en Mecánica y Ciencias de la Producción. Guayaquil - Ecuador. 100 p.

Pedan V.; Fischer, N.; Rohn, S. 2015. An online NPHPLC-DPPH method for the determination of the antioxidant activity of condensed polyphenols in cocoa. Food Research International 89 (Part.2): 890900.

Pereira-Caro, G.; Borges, G.; Nagai, C.; Jackson, M. C.; Yokota, T.; Crozier, A., Ashihara, H. 2013. Profiles of Phenolic Compounds and Purine Alkaloids during the Development of Seeds of Theobroma cacao cv. Trinitario. J. Agric. Food Chem. 61(2): 427-434.

Quarmine, W.; Haagsmaa, R.; Sakyi-Dawson, O.; Asantec, F.; van Huis, A.; Obeng-Ofori, D. 2012. Incentives for cocoa bean production in Ghana: Does quality matter? NJAS - Wageningen Journal of Life Sciences 60-63: $7-14$.

Rabadan-Chávez G.; Quevedo-Corona, L.; Garcia, A. M.; Reyes-Maldonado, E.; Jaramillo-Flores, M.E. 2016. Cocoa powder, cocoa extract and epicatechin attenuate hypercaloric diet-induced obesity through enhanced $\beta$ oxidation and energy expenditure in white adipose tissue. Journal of Functional Foods 20: 54-67.

Rios, V.C. 2012. Estadística y diseño de experimentos. Universidad Nacional de Ingeniería, Editorial Universitaria, Perú. 261 p.

Saltini, R.; Akkerman, R.; Frosch, S. 2013. Optimizing chocolate production through traceability: A review of the influence of farming practices on cocoa bean quality. Food Control 29(1): 167-187. 
Sarriá, B; Martínez-López, S.; Sierra-Cinos, J. L.; GarciaDiz, Luis; Goya, L. Mateos, R.; Bravo, L. 2015. Effects of bioactive constituents in functional cocoa products on cardiovascular health in humans. Food Chemistry 174: 214-218.

Torres, M. 2012. Influence of the characteristics and processing of cocoa beans in the physicochemical composition and sensory properties of black chocolate. Doctoral thesis, Universitat Rovira Virgili. Cataluña, España.
Trognitz, B.; Cros, E.; Assemat S.; Davrieux, F.; ForestierChiron, N.; Ayestas, E.; Kuant A.; Scheldeman, X.; Hermann, M. 2013. Diversity of Cocoa Trees in Waslala, Nicaragua: Associations between Genotype Spectra, Product Quality and Yield Potential. PLoS ONE 8(1): e54079.

Zambrano, A.; Romero, C.; Gomez, A. 2010. Chemical evaluation of aroma and flavor precursors of merideño Criollo cacao during fermentation in two edaphoclimatic conditions. Venezuela. Trop. 60 (2): 211-219. 